\title{
Demographics Characteristics and Analysis of Malocclusions of Orthodontic Patients Seen at IIUM Dental Specialist Clinic, Kuantan, Pahang
}

\author{
Ismail Ka, Ghazali@Suhaimi SS ${ }^{\mathrm{a}}$, Abu Bakar $\mathrm{N}^{\mathrm{b}}$, Mokhtar $\mathrm{KI}^{\mathrm{c}}$ and Kharuddin $\mathrm{AF}^{\mathrm{d}}$ \\ ${ }^{a}$ Undergraduate Student, Kulliyyah of Dentistry, International Islamic University Malaysia \\ ${ }^{b}$ Unit of Orthodontics, Kulliyyah of Dentistry, International Islamic University Malaysia \\ 'Unit of Oral Biology, Kulliyyah of Dentistry, International Islamic University Malaysia \\ ${ }^{d}$ Department of Computational and Theoretical Sciences, Kulliyyah of Science, \\ International Islamic University Malaysia
}

\section{ABSTRACT}

Introduction: Malocclusion is one of the most common dental problems observed. Limited data is currently available regarding the demographics of malocclusion observed locally. Materials And Methods: This is a retrospective study where 770 patients were recruited from May 2009 till December 2014. 560 orthodontic study models that met the inclusion criteria were examined and the malocclusions were classified according to the British Standard Institute (BSI) incisor classification. Demographic pattern and their relationship were analysed by structural equation modelling using SPSS (version 23.0). Results: From 560 study models analysed, $72 \%$ were female. The age of the patients ranges from 7-12 years old (17.1\%), 13-17 years old (55.9\%) and $>18$ years old (27.0\%). Majority of the patients were Malay followed by Chinese $(5.7 \%)$, Indian (1.8\%) and other races (1.8\%) Treatments received were fixed appliances (FA) (60.0\%), removable appliances (RA) $(12.5 \%)$, functional appliances (FnA) (1.1\%), combination of RA and FA (16.1\%), combination of FnA and FA (2.1\%) and consultation (8.2\%). Types of malocclusions observed were Class I (25.7\%), Class II/1(32.7\%), Class II/2 (7.5\%) and Class III (34.1\%). There was significant association $(\mathrm{p}<0.05)$ between age and gender towards the types of malocclusions and treatments received were observed. Conclusion: Age and gender play significant role in determining the types of treatment received by patients with malocclusion. Data obtained will be beneficial for departmental future management and clinical planning.

KEYWORDS: Demographics, Orthodontic, Malocclusion

\section{INTRODUCTION}

Malocclusion is one of the most common dental problems observed apart from dental caries, gingival disease and dental fluorosis. ${ }^{1}$ A malocclusion is defined as an irregularity of the teeth or an abnormal relationship of the dental arches beyond the range of what is accepted as normal. ${ }^{2}$ This condition may lead to distorted facial appearance, limited masticatory function, increased risk of dental trauma, and compromise the quality of life. ${ }^{3}$ There are two common ways to classify malocclusion; Angle classification and British Standard Institute (BSI) classification. Angle's classification; using the occlusal relationship of the permanent first molar and the malocclusion can be divided into three classifications; Class I, Class II and Class III malocclusion. British Standard Institute Classification (1983) determines the types of malocclusion by looking at the relationship of the

Corresponding author:

Asst. Prof. Dr Noraini Abu Bakar

Unit of Orthodontics, Kulliyyah of Dentistry

International Islamic University Malaysia

Jalan Sultan Ahmad Shah, Bandar Indera Mahkota

25200 Kuantan, Pahang, Malaysia

Tel: +609-570 5466 (Office)

Fax: $+609-5705580$

Email:nor_aini@iium.edu.my lower incisor occlusion onto the palatal surface of upper incisors. ${ }^{4}$ This incisor classification has three categories of Class I, Class II and Class III. Class II malocclusion can be further divided into Class II division I (II/1) and Class II division II (II/2). ${ }^{5} \mathrm{BSI}$ was considered to be more reliable than Angle's classification because the posterior teeth did not influence and in conflict with the incisor occlusion type. ${ }^{6}$ Hence, in this research, BSI was used as BSI was seen to be more valid than Angle's in representing patient's malocclusion.

The occurrence of different types of malocclusions varies according to geographical location. For instance, investigation of malocclusion pattern in 125 patients attending Department of Orthodontics of BVU Dental College and Hospital in Sangli, India reported that the commonest type of malocclusion was Angle's class II which was seen in $60(48 \%)$ of patients. ${ }^{7}$ On the other hand, the prevalence of malocclusion in the Hungarian population found that a Class I occlusion was $52.8 \%$ of the subjects. ${ }^{8}$ There was a significantly higher prevalence of Class III occlusion among the Chinese and Malays as compared to the Indians in a study done in Malaysia.9 Additionally, the demands for the treatment of malocclusion diversify with social and cultural conditions. ${ }^{10}$ Differences in the age range of the populations studied, ethnicity, and the number of subjects examined could explain some of the variations. ${ }^{11}$ 
International Islamic University Malaysia (IIUM) Orthodontic Specialist Clinic in Kuantan Campus is located in the state of Pahang and offers orthodontic treatment to the patients covering mainly the state of Pahang and south of Terengganu. The number of orthodontic cases has increased year by year since the orthodontic specialist clinic was first established in the year 2009. It is important to study the demography of the patients seen and treated, to further understand the pool of patients, types of malocclusions and treatment given. These facts can be further utilized in management and clinical planning. Therefore, the aim of this research was to establish a baseline for demography of orthodontic patients seen in IIUM Orthodontic Specialist Clinic and to analyse types of malocclusion and treatment given. Additionally, the interrelationship between age and gender with types of malocclusion and treatment given also analysed. The database of the current research will also provide significant information to facilitate future research.

\section{MATERIALS AND METHODS}

This research was a retrospective study of all orthodontic patients treated by specialists at Orthodontic Specialist Clinic, Kulliyyah of Dentistry, IIUM from May 2009 until December 2014. Ethical approval was obtained from IIUM Research Ethics Committee (IREC) (reference number: IIUM/305/14/11/2/IREC 314). All the patients' details (secondary data) were retrieved namely from the waiting list "Logbook", fixed appliance list, patients' folders, Planmeca Romexis ${ }^{\circledR}$ software, and Amaryllis or PearlDental database. All orthodontic study models were examined. Those who met the inclusion criteria, mainly; patients with complete data on age, gender, race, malocclusion and treatment types were recruited. The incisor classification using the British Standard Institute (BSI) incisor classification (Table 1) were obtained and placed in the study protocol form. Exclusion criteria include broken study models and incomplete information. A total of 770 study models were retrieved. However, only 560 patients or study models that fulfilled the inclusion criteria were used for further analysis. Training on malocclusions classification with specialists was done and subsequently inter-examiner calibration was carried out on 10 study models to achieve a synchronized agreement between the two examiners. Kappa value for the incisor relationship was 1.00 indicating almost perfect agreement between the two examiners. $^{12}$

\section{RESULTS}

\section{Statistical analysis}

The data was analysed using the SPSS (version 23.0). Descriptive analysis was done to determine the patients' profile. Simple linear regression and multivariate regression analysis were used to assess the total effects of patients with malocclusion and treatment received at IIUM Dental Clinic, taking interactions between demographics pattern into account. Results were considered significant when $\mathrm{p}<0.05$.

The demographics of the patients is shown in Table 2 whilst Table 3 shows the distribution of malocclusion and Figure 1 shows the treatment type received.

Table I: The BSI incisor classification (British Standard 4492)

\begin{tabular}{|c|c|}
\hline $\begin{array}{l}\text { Incisor } \\
\text { relationship }\end{array}$ & Definition \\
\hline Class I & $\begin{array}{l}\text { The lower incisor edges occlude with } \\
\text { or lie immediately below the } \\
\text { cingulum plateau of the upper } \\
\text { central incisors. }\end{array}$ \\
\hline Class II & $\begin{array}{l}\text { The lower incisor edges lie posterior } \\
\text { to the cingulum plateau of the upper } \\
\text { incisors. There are two subdivisions } \\
\text { of this category: }\end{array}$ \\
\hline Division 1 & $\begin{array}{l}\text { The upper central incisors are } \\
\text { proclined or of average inclination } \\
\text { and there is an increase in overjet. }\end{array}$ \\
\hline Division 2 & $\begin{array}{l}\text { The upper central incisors are } \\
\text { retroclined, the overjet is usually } \\
\text { minimal or may be increased. }\end{array}$ \\
\hline Class III & $\begin{array}{l}\text { The lower incisor edges lie anterior to } \\
\text { the cingulum plateau of the upper } \\
\text { incisors, the overjet is reduced or } \\
\text { reversed. }\end{array}$ \\
\hline
\end{tabular}

Table II: Demographic profile of the orthodontic patients attending IIUM Dental Clinic from May 2009-December 2014

\begin{tabular}{|c|c|c|}
\hline Profiles & $n=560$ & $\% *$ \\
\hline \multicolumn{3}{|l|}{ Gender } \\
\hline Male & 157 & 28.0 \\
\hline Female & 403 & 72.0 \\
\hline \multicolumn{3}{|l|}{ Age (years) } \\
\hline $0-6$ & 0 & 0 \\
\hline $7-12$ & 96 & 17.1 \\
\hline $13-17$ & 313 & 55.9 \\
\hline$\geq 18$ & 151 & 27.0 \\
\hline \multicolumn{3}{|l|}{ Race } \\
\hline Malay & 508 & 90.7 \\
\hline Chinese & 32 & 5.7 \\
\hline Indian & 10 & 1.8 \\
\hline Others & 10 & 1.8 \\
\hline
\end{tabular}

*standardized to the nearest $0.1 \%$

Table III: Distribution of Malocclusion cases Classified according to BSI Incisor Classification, $n=560$

\begin{tabular}{|c|c|c|}
\hline Incisor classification & $n=560$ & $\% *$ \\
\hline Class I & 144 & $25.7 \%$ \\
\hline \multicolumn{3}{|l|}{ Class II } \\
\hline Division 1 & 183 & $32.7 \%$ \\
\hline Division 2 & 42 & $7.5 \%$ \\
\hline Class III & 191 & $34.1 \%$ \\
\hline
\end{tabular}

*standardized to the nearest $0.1 \%$ 


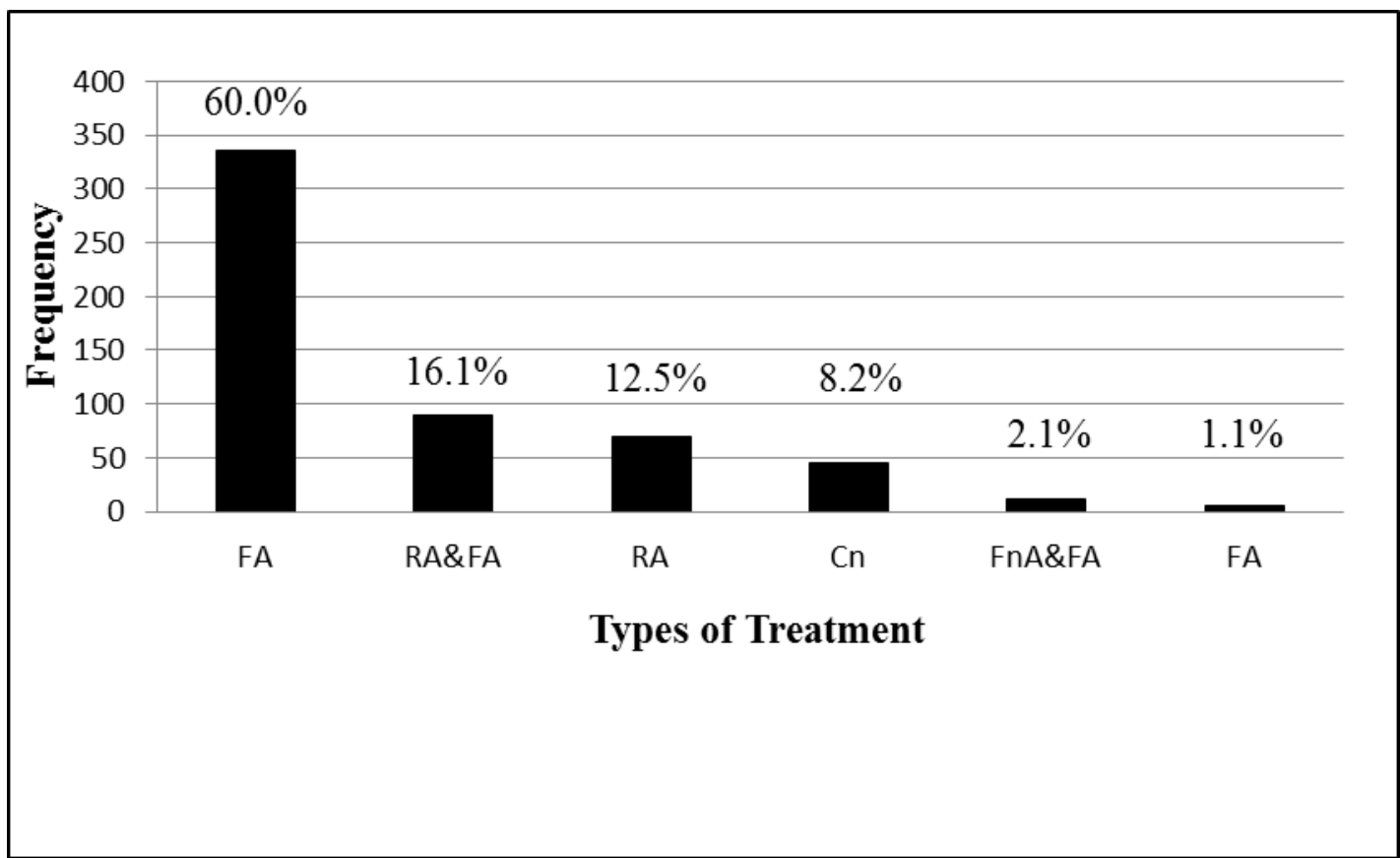

Figure 1: Distribution of types of treatments received by orthodontic patients in IIUM Dental Clinic, $\mathrm{n}=560$. Abbreviation: FA: Fixed Appliances; RA: Removable Appliances; Cn: Consultation; FnA: Functional Appliances

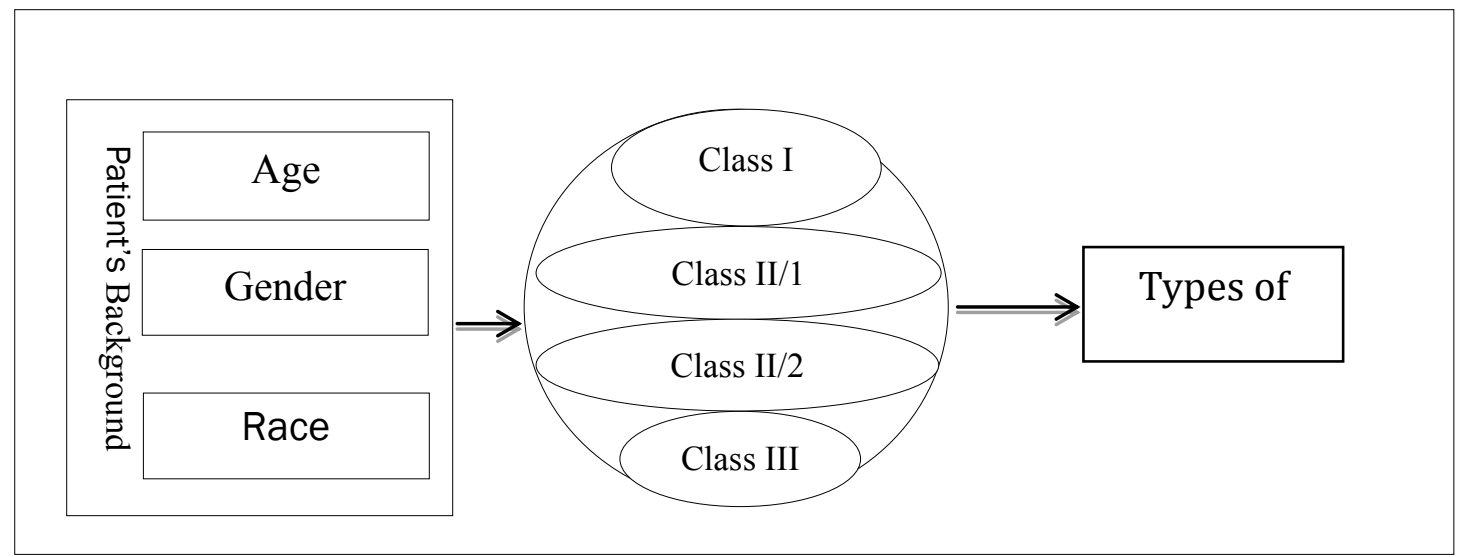

Figure 2: A draft model relationship of indications (patient's background), mediators (type of malocclusion) and outcome (dental treatment)

Conceptual framework was used to validate the relationship between demographic factors, type of malocclusion and their dental treatment. $\mathrm{n}$ There was no significant association between race and type of malocclusion and treatment received as shown in Figure thus it was eliminated from the model framework (Figure 3).

Results from the regression analysis (Table 4) showed that there was significant relationship between age and gender towards types of malocclusion and treatment received However, there was no significant relationship between types of malocclusion and treatment received. Interestingly, there was significant relationship of between age and gender towards types of treatment mediated by the types of malocclusion.

\section{DISCUSSION}

Many studies have been published regarding the demographic of orthodontic patients in various orthodontic practice sites such as in Pakistan,
United States and Tanzania and also studies that look at the distribution of malocclusion in various populations. ${ }^{13-17}$ However, there was a very limited data in this area specifically for Malaysian population. The findings from this research will add on to the pool of knowledge gathered from other studies that have been carried out in Malaysia. 9, 18-20 Malaysian population is multi-races, which consist of Malay, Chinese, Indian and others. The 2010 Population and Housing Census of Malaysia (Census 2010) reported that Pahang, with 1.5 million in population consist of $79 \%$ Bumiputra, $16.2 \%$ Chinese and $4.4 \%$ Indian. This fact was reflected in our study, as Malays was the most frequent $(90.7 \%)$ attender of IIUM Orthodontic Specialist Clinic which was also supported by other study. ${ }^{20}$ Similar to previous studies, the current study showed no significant relationship between race and malocclusion types although a survey reported that the Chinese and Malay had almost similar distribution of the different types of occlusion. ${ }^{9}$ Findings from this research showed that $55.9 \%$ of 
Table IV: Regression analysis

\begin{tabular}{lccc}
\hline Model hypothesis $(\mathrm{H})$ & $\begin{array}{c}\mathrm{R}^{2} \\
\text { value }\end{array}$ & $\begin{array}{c}\text { ANOVA } \\
\mathrm{F} \text { value }\end{array}$ & $\mathrm{P}$ value* $^{*}$ \\
\hline $\begin{array}{l}\text { relationship of age and } \\
\text { gender towards }\end{array}$ & 0.018 & 5.139 & 0.006 \\
treatments' types \\
$\begin{array}{l}\text { relationship of age and } \\
\text { gender towards }\end{array}$ & 0.013 & 3.539 & 0.030 \\
$\begin{array}{l}\text { malocclusions' types } \\
\text { relationship of } \\
\text { malocclusion towards }\end{array}$ & 0.004 & 2.337 & 0.127 \\
$\begin{array}{l}\text { treatments' types } \\
\text { relationship of age and } \\
\text { gender towards } \\
\text { malocclusions' and }\end{array}$ & 0.018 & 5.139 & 0.006 \\
treatments' types & & & \\
\hline
\end{tabular}

the orthodontic patients were between the ages of 13 to 17 years old which is consistent with other studies. ${ }^{13,18,19}$ It shows that majority of patients were in the age range where their main concern is their appearance and social acceptance. ${ }^{21}$ This is also deemed to be the best timing to treat malocclusions with fixed appliances as most patients are in permanent dentition and significant changes that occurred during the adolescent growth spurt will greatly affects the stability of the result after orthodontic treatment. ${ }^{22}$ From this research, majority of the patients were females which is consistent with other studies. ${ }^{13,17,19,23}$ This may suggests a greater tendency of women seeking orthodontic treatment. ${ }^{24-26}$ This research also showed that the relationship between gender and type of malocclusion was not significant and this was also reported by other study. ${ }^{27}$ Our findings found that majority were Class III malocclusion type and this is in agreement with other studies. ${ }^{28,} 29$

Looking at the treatment type, Fixed Appliance (FA) was indicated if accurate tooth movements were needed but FA was not as efficient as functional appliances (FnA) or removable appliances (RA) in moving blocks of teeth. FnA make use of the timing of growth and tooth eruption in treating malocclusion. Meanwhile, RA works alone or used as an adjunct or assistant prior to the treatment that needed FA. Each type of treatments has their own indication. In designing the suitable treatment for the patient, there is no rigid or specific treatment outlined for each type of malocclusion. Treatment depends on various factors such as stage of dental development, growth expectations, patient's cooperation and others. ${ }^{30}$ In this study, FA was the most frequent treatment received and this is in concurrence with other study. ${ }^{13}$

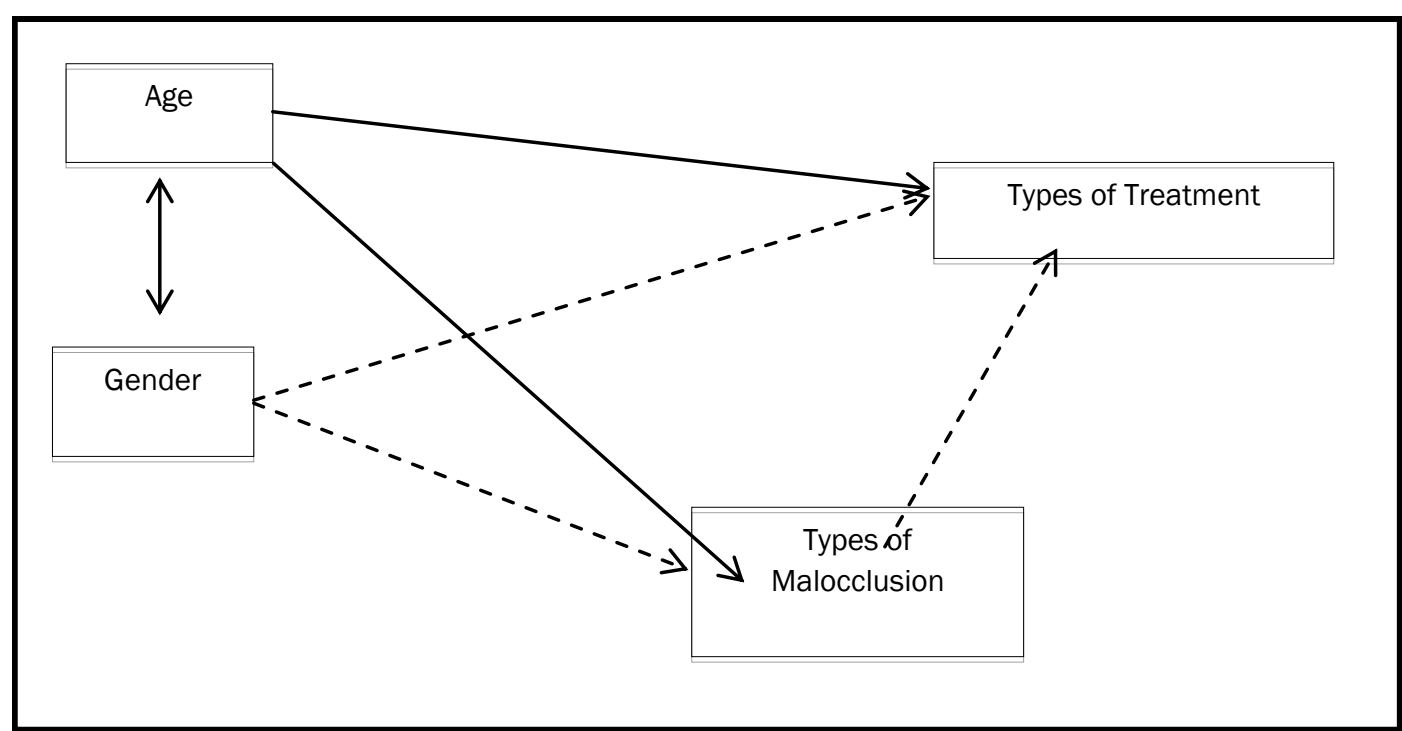

Figure 3: Significant Model Hypothesis of SEM Legends:

$$
\begin{aligned}
& \text { : Significant relationship } \\
& \text { : Insignificant relationship } \\
& \text { : Interrelationship }
\end{aligned}
$$

\section{CONCLUSIONS}

In summary, our study revealed that the majority of the patients that seek orthodontics treatment at IIUM Orthodontic Specialist Clinic age range were 1317 years old, female, with Class III malocclusions. Results also showed that Malay was the dominant race and Fixed Appliances was the most popular choice of treatment. Interestingly, the analysis obtained from this study concluded that age and gender had significant effect towards types of treatment mediated by the types of malocclusion.
Data obtained will be beneficial for literature, future dental management and clinical planning.

\section{ACKNOWLEDGEMENTS}

The authors would like to acknowledge IIUMResearch Initiative Grant Scheme (IIUM-RIGS-15- 045 -0045) for the financial support and staff of Department of Orthodontics, Kulliyyah of Dentistry, IIUM for their assistance throughout this research. 


\section{REFERENCES}

1. Dhar V, Jain A, Dyke TEV, Kohli A. Prevalence of gingival diseases, malocclusion and fluorosis in school-going children of rural areas in Udaipur district. J. Indian Soc. Pedod. Prev. Dent 2007; 25: 103-105.

2. Walther DP, Houston WJB, Jones ML, et al. Walther and Houston's orthodontic notes. Oxford: Wright, 1994.

3. Claudino D, Traebert J. Malocclusion, dental aesthetic self-perception and quality of life in a 18 to 21 year old population: a cross section study. BMC Oral Health 2013; 13:3.

4. Backlund E. Overbite and the incisor angle. The Transactions of the European Orthodontic Society 1958; 277-286.

5. Proffit WR, Fields HW, Sarver DM. Contemporary Orthodontics. St. Louis, Mo: Mosby Elsevier, 2007.

6. Du SQ, Rinchuse DJ, Zullo TG. Reliability of three methods of occlusion classification. Am J Orthod Dentofacial Orthop 1998; 113(4): 463 470.

7. Nanjannawar L, Agrawal JA, Agrawal M. Pattern of malocclusion and treatment need in orthodontic patients: an institution-based study. World J Dent 2012; 3(2): 136-140.

8. Gabris K, Marton S, Madlena M. Prevalence of malocclusions in Hungarian adolescents. The European Journal of Orthodontics 2006; 28 (5): 467-470.

9. Woon KC, Thong YL, Kadir AR. Permanent dentition occlusion in Chinese, Indian and Malay groups in Malaysia. Australian Orthodontic Journal 1989; 11(1): 45-48.

10. Mugonzibwa EA, Kuijpers-Jagtman AM, Van 'Thof MA. Demand for orthodontic treatment among 9-18 year-olds seeking dental care in Dar -Es-Salaam, East African Medical Journal 2004; 81(1): 3.

11. Abu Al-Hajja ESJ, Al-Khateeb SN, Al-Nimri KS. Prevalence of malocclusion in 13-15 year-old North Jordanian school children. Community Dent. Health 2005; 22(4): 266-721.

12. Viera AJ, Garret JM. Understanding Interobserver Agreement: The Kappa Statistic. Family Medicine 2005; 37(5): 360-363.

13. Shahzad S, Alam J, Ashfaq M. An analysis of orthodontic patients treated during 2001 at Khyber College of Dentistry, Peshawar. Pakistan Oral \& Dent. Jr 2002; 22(2): 149-150.

14. Bollen AM, Cunha-Cruz J, Hujoel PP. Secular trends in preadult orthodontic care in the United States: 1942-2002. American Journal of Orthodontics and Dentofacial Orthopedics 2007; 132: $579-85$.

15. Solomon ES, Ceen RF. Demographic Characteristics of Orthodontic Practice Sites in the United States. American Journal of Orthodontics and Dentofacial Orthopedics 2006; 133(4): 115-119.

16. Mtaya M, Astrom AN, Brudvik P. Malocclusion, psycho-social impacts and treatment need: a cross sectional study of Tanzanian primary school-children. BioMed Central Oral Health 2008; 8: 14.

17. Mtaya M, Brudvik P, Astrom AN. Prevalence of malocclusion and its relationship with sociodemographic factors, dental caries and oral hygiene in 12-14 year-old Tanzanian schoolchildren. Eur. J. Orthod 2009; 31: 467476.

18. Abdullah AAA, Yassin Z, Zamzam N. Reasons for seeking orthodontic treatment: A pilot study. Annal. Dent. Univ. Malaya 2001; 8: 13-19.

19. Abdul Wahab RM, Idris $\mathrm{H}$, Yacob H, Zainal Ariffin SH. Cephalometric and malocclusion analysis of Kadazan Dusun ethnic orthodontic patients. SainsMalaysiana 2013; 42(1): 25-32.

20. Mohd Zamzuri SZ, Abdul Razak I, Esa R. Normative and perceived need for treatment of malocclusion among Malaysian adolescents. J. SainsMalaysiana 2014; 43(7): 1037-1043.

21. Marques LS, Pordeus IA, Ramus-Jorge ML, et al. Factors associated with the desire for orthodontic treatment among Brazilian adolescents and their parents. BMC Oral Health 2009; 9:34.

22. Mitchell L. An introduction to orthodontics. $3^{\text {rd }}$ ed. United States: Oxford University Press, 2007.

23. Komazaki Y, Fujiwara T, Ogawa T, et al. Prevalence and gender comparison of malocclusion among Japanese adolescents: A population-based study. Journal of the World Federation of Orthodontists 2012; 1: 67-72.

24. Sergl GH, Zentner A. A study of psychosocial aspecs of adult orthodontic treatment. Int. J. Orthod. Orthognath. Surg 1997; 12(1): 17-22.

25. Tung AW, Kiyak HA. Psychological influences on he timing of orthodontic treatment. Am. J. Orthod. Dentofacial Orthop 1998; 113(1): 29 39.

26. Tuominen ML, Tuominen RJ, Nystrom ME. S subjective orthodontic treatment need and perceived dental appearance among Finnish adults with or without previous orthodontic treatment. Community Dent. Health 1994; 11 (1): 29-33.

27. Al-Maqtari RA, Abdul Kadir $\mathrm{R}$, Awang $\mathrm{H}$, Zamzam NM. Assessment of Malocclusion among Yemeni adolescents Using Canine and Incisor Classifications. Journal of Advanced Medical Research 2012; 2(4): 153-159.

28. Lew KK, Foong WC, Loh E. Malocclusion Prevalence in an Ethnic Chinese Population. Australian Dental Journal 1993; 38: 442-449.

29. Elfseyie MTM. A Study of Occlusal Features of Malay Adults and 12 Years Old Schoolchildren. 2013; Available at: http:// ir.uitm.edu.my/12276/1/TM_MAJDA\%20T.\% 20M.\%20ELFSEYIE\%20DS\%2013_24.pdf.Accessed January 11, 2016.

30. Bishara SE. Textbook of Orthodontics. Philadelphia, Pa: W.B. Saunders Company, 2001. 